\title{
A crítica de Hegel e Agamben ao liberalismo político
}

Joel Decothé Junior ${ }^{1}$

DOI 10.20399/P1982-999X.2016v1n1pp38-57

\begin{abstract}
Resumo: O liberalismo político recebe a veemente crítica de dois pensadores de períodos bem distintos da história da filosofia: pensamos aqui em Hegel e Agamben. Neste texto a questão que nos serve de referência para a reflexão desenvolvida é a crítica ao liberalismo e a sua postura política que confia no contrato como garantia de consenso social. Para tanto, num primeiro momento discorro sobre a concepção de Estado e poder político presente na crítica que Hegel enceta a este modelo político. Isso implica na questão da mediação entre a força estatal em termos universais e a força da sociedade civil no campo da particularidade. No desenvolvimento do tema, busco compreender por meio da reflexão de Agamben via o seu vitalismo a sua crítica ao modelo de liberalismo político. Agamben em sua empreitada enfatiza o valor da categoria de vida em sua condição de nudez. Importa ainda frisar que em meio a esta aporia, o filósofo italiano coloca em jogo a proposta de uma política que vem e a possibilidade de uma ética pautada pela categoria de forma-de-vida como resistência aos cálculos biopolíticos que tendem a sacralização do fator jurídico na arquitetura das democracias liberais.
\end{abstract}

Palavras-chave: Liberalismo; Crítica; Estado; Vida.

Abstract: Political liberalism receives strong criticism of two thinkers of very different periods of the history of philosophy: think here in Hegel and Agamben. In this paper the question that serves as a reference for the developed reflection is the critique of liberalism and its political stance that relies on contract as a guarantee of social consensus. Therefore, at first I wonder about the conception of state and political power in this criticism that Hegel initiates this political model. This implies the question of mediation between state power in universal terms and the strength of civil society in the field of particularity. On the theme of development, we seek to understand through reflection of Agamben via your vitalism its criticism of the political liberalism model. Agamben in this endeavor underscores the value of the category of life in its nakedness condition. It is also important to note that in the midst of this quandary, the Italian philosopher puts at stake the proposal for a policy that comes and the possibility of an ethic marked by the de-form-life as resistance to bio-political calculations tend to sacralization of the legal factor in liberal democratic architecture.

Keywords: Liberalism; Critical; State; Life.

\section{Introdução}

Neste texto tenho a intenção de perseguir e esboçar sinteticamente a construção teorética de alguns elementos e categorias referentes à crítica que Hegel enceta ao liberalismo político moderno. $\mathrm{O}$ acento na teorização dialética que Hegel concede em termos de existência de uma suposta primazia da figura do Estado em detrimento da sociedade liberal burguesa não se confirma. Como iremos ver abaixo, Hegel é equilibrado ao fazer uma justa mediação entre alguns aspectos fundamentais e próprios do liberalismo político e outros princípios referentes à gênese e estrutura política do Estado moderno. Conferiremos também que para Hegel a existência de autonomia dos cidadãos no ceio da sociedade civil gera uma série de possíveis satisfações. Isto só pode

\footnotetext{
${ }^{1}$ Mestre em filosofia pela Universidade do Vale do Rio dos Sinos (UNISINOS). Bacharel em teologia pela Escola Superior de Teologia (EST); Licenciado em filosofia pela Universidade do Vale do Rio dos Sinos (UNISINOS); Especialização em Teologia pela Escola Superior de Teologia (EST).
} 
acontecer em razão da idealização e concretização dos empreendimentos e projetos de interesse individual, pois são estes que conferem aos sujeitos a possibilidade de realizarem neste arranjo social as suas aspirações de ordem subjetiva. Sendo assim, veremos que neste horizonte social, as ações efetivadas por cada sujeito acabam sendo pautadas pela categoria de liberdade a qual é dever do Estado garantir.

No desdobramento deste estudo, conferiremos ainda as reflexões de outro pensador que também pondera a respeito desta dinâmica de crítica ao liberalismo político e neste caso falo do filósofo italiano Giorgio Agamben. Este pensador segue os rastros da crítica hegeliana, pois na sua visão se ostenta um olhar crítico diante da instituição democrática liberal. Esta postura crítico-filosófica expressa-se com ampla evidência, e isto se dá desde a sua formulação propositiva no que tange a crítica ao dispositivo do direito e a sacralização do poder jurídico-político-econômico vigente na sociedade do espetáculo operante nas democráticas contemporânea. Abordo ainda um pouco da proposta provocativa lançada por Agamben nos termos de uma categoria nuclear presente em seu pensamento filosófico, a saber, a noção de uma política que vem. Importante ainda é cotejar a pertinente distinção que este pensador realiza em relação às categorias de contrato e vida. Encerro tentando correlacionar e confrontar as posições de Hegel e Agamben diante da aporia política liberal.

\section{Estado e poder político na crítica de Hegel ao liberalismo político}

Hegel é um pensador que utiliza com muita precisão em seu trabalho filosófico o expediente da metodologia dialética. Podemos perceber isto em sua crítica ao liberalismo político, pois ele não tolhe a força soberana do Estado em detrimento da força burguesa e individualizante da sociedade civil. Para Hegel o Estado se constitui a partir de dois princípios fundamentais: (i) a identificação entre os governantes e (ii) a supressão da heterogeneidade. Na perspectiva hegeliana acontece a utilização especulativa no que diz respeito aos elementos da identidade e da totalidade. Hegel faz uma distinção importante entre o Estado e a sociedade civil. Neste jogo de forças políticas, o Estado na concepção hegeliana é superior em sentido amplo à sociedade civil instituída ${ }^{2}$. O Estado para Hegel ao contrário do que prega o liberalismo político é o cume da noção de universalidade, pois na noção de Estado hegeliana há uma espécie

\footnotetext{
${ }^{2}$ RAMOS, A. C. "A crítica de Schmitt e de Hegel ao liberalismo". In: Trans/ Form/Ação, São Paulo, v. 18, p. 105-119, 1995. Disponível em: <<http:www.//revistaseletronicas .trans/form/ação.org.br〉〉. Acesso em: 06 jan de. 2015.
} 
de politização holística da sociedade. Na perspectiva de Hegel a esfera do Estado é como uma arena de embates onde aquilo que é político e até mesmo econômico, tende em vista que a economia de mercado pertencente à sociedade civil reflete uma distinção sutil desta conjuntura que não faz parte em absoluto do raio de ação propriamente dito do Estado. Em Hegel a esfera pública e a esfera privada dialogam dialeticamente na busca de um consenso para o estabelecimento e vigência do contrato. Hegel encara o fato da existência do poder estatal ser real e racional algo que não exclui a presença ativa na conjuntura social do cidadão como pessoa autônoma e a existência da figura atuante do burguês. Logo, a dialética entre privado e público fomenta a estruturação de uma ordem política mista vigente na estrutura civil condizente a sociedade na modernidade ${ }^{3}$.

Sendo assim, podemos notar que Hegel se opõe a concepção política liberal, onde o que se quer é o estabelecimento da condição e existência de um Estado fragilizado, mínimo e neutro. Mesmo que Hegel conceda tamanha importância à política de Estado, podemos dizer dialeticamente que a intervenção do Estado e seu investimento político no âmbito social não se constituem como algo forte e linear. A identidade que leva a marca da racionalidade, da ética e da politicidade do Estado hegeliano deseja propor uma postura universalista da eticidade ${ }^{4}$. Isto transcende os valores e interesses individualistas propagados pela ideologia política liberal. A sociedade burguesa liberal no espaço estatal hegeliano não é soberana em termos de decisão e imposição de seus interesses particulares. Então, podemos afirma que é neste quesito que reside a grande crítica de Hegel ao liberalismo, pois a sua proposta é a de um intercâmbio dialético no funcionamento da dinâmica social entre o universal e o individual.

\footnotetext{
${ }^{3}$ BAVARESCO, A. A fenomenologia da opinião pública: a teoria hegeliana. Coleção Filosofia. São Paulo: Edições Loyola, 2003, p. 92.

${ }^{4}$ Cf. BORGES. M. L. A. História e Metafísica em Hegel: sobre a noção de espírito do mundo. Porto Alegre: EDIPUCRS, 1998, p.151: A eticidade é, portanto, a identidade concreta do Bem e da vontade subjetiva (RPH § 141), pois nem o Bem sem a subjetividade, nem a subjetividade sem uma existência na vida ética de um povo, podem-se constituir numa verdadeira realização da Idéia de liberdade. A vida ética é a plena objetivação do espírito, ela é algo objetivo que se materializa, sem deixar de ser o produto de uma pluralidade de autoconsciências, necessitando do assentimento dos indivíduos e do reconhecimento de que, o que assim se dá uma existência, é a racionalidade de uma vontade livre. A eticidade, assim como o espírito objetivo, apresenta uma tripartição: a família, momento ainda natural do espírito ético; a sociedade civil, na qual os indivíduos associam-se para garantir o suprimento de seus carecimentos, bem como a segurança de sua pessoa e propriedade, constituindo a esfera do regramento das necessidades particulares e coletivas e, por fim o Estado.
} 
$\mathrm{Na}$ reflexão de Hegel, o campo da sociedade civil e burguesa tem a sua identidade demonstrada na junção formal de indivíduos que por meio de seu trabalho, lutam pela realização de suas necessidades e satisfações individuais. A sociedade civil seria aquele estado de necessidade e de entendimento que é caracterizado pela liberdade subjetiva dos seus componentes. Notemos que mesmo com esta premissa e, apesar de esta ser orientada pelo direito privado e por leis vigorantes em seu mundo, a sociedade civil e burguesa não consegue por si mesma atingir a condição política de atender plenamente o interesse que a esfera pública estatal sustenta e como implicação disto é que surgem os conflitos com o poder estatal. É nesta dimensão que entra efetivamente a presença forte do Estado ao paramentar as relações sociais com o sei aparato jurídico. Desta forma o poder do Estado acaba contrariando os fundamentos do liberalismo político que é um defensor do Estado mínimo. Para Hegel o Estado tem uma função política fundamental que é a de defender o poder legislativo para que toda a sociedade participe de sua vida de um modo singular e como membros da arquitetura social ${ }^{5}$.

O Estado tem a força de ser superior a sociedade civil e burguesa imprimindo a sua forma de vida social pautada na eticidade que tem as condições necessárias de produzir um tipo de universalismo que faz a diferença entre os interesses individuais e os interesses socioeconômicos coletivos. Para Hegel a autonomia da sociedade civil diante da soberania do Estado não concede privilégios aos fatores econômicos em detrimento dos fatores políticos como defendem os ideais políticos dos liberais, por exemplo, com a noção de mercado livre. E muito menos com a presunção de uma suposta subserviência do público sobre o privado. Logo, Hegel define a função do Estado em termos de ser uma espécie de necessidade externa e, em razão disto, o mesmo se constitui como o fim iminente da família e da sociedade civil nas questões que envolvem os interesses tanto pessoais como coletivos da sociedade como um todo ${ }^{6}$.

A meta do liberalismo político pode ser descrita como o esforço de tornar a ação do Estado frágil e minimalistamente diminuta nos âmbitos político, econômico e jurídico. Para esta corrente de pensamento político o poder estatal carrega consigo uma imagem estritamente pejorativa. Na perspectiva hegeliana tal unilateralismo pode se tornar uma postura autoritária se não for bem ponderada e mediada. Tal visão de Estado

\footnotetext{
${ }^{5}$ MARX, K. Crítica da filosofia do direito de Hegel 1843; tradução de Rubens Enderle e Leonardo de Deus; [supervisão e notas Marcelo Backes]. - [2.ed revista]. - São Paulo: Boitempo, 2010, p.133.

${ }^{6}$ ROVIGHI, S. V.. História da filosofia contemporânea: do século XIX à escolástica contemporânea. Tradução Ana Pareschi Capovilla; $4^{a}$ edição: maio de 2011. São Paulo: Edições Loyola, 2011, p. 80-84.
} 
segue numa direção diametralmente aposta a visão de Hegel sobre o Estado. Hegel leva em conta o fato de que a força estatal se constitui como uma instituição positiva e que deve estar presente e atuante na vida política da sociedade civil. No pensamento político de Hegel o Estado é o detentor natural do poder, pois somente com a detenção do poder pelo Estado é que os cidadãos poderão naturalmente realizar as suas metas pessoais, assim como a efetualidade da ação da eticidade pode ser realizada no exercício da liberdade que os caracteriza a vida tripartite da família, da sociedade civil e a do próprio Estado dentro da dialética concernente à dinâmica social que envolve a vida ética cotidiana. Porém, cabe frisar que neste caso o Estado tem uma finalidade que não serve apenas como puro meio de arbitragem e obtenção de garantia dos interesses privados. $\mathrm{O}$ Estado na compreensão hegeliana é quem detém o poder de estabelecer as leis e, assim temos o resultado explícito e concreto da positividade do Estado na operatividade de sua ação jurídico-política. Conforme argumenta Hegel:

Em face do direito privado e do interesse particular, da família e da sociedade civil, o Estado é, por um lado, necessidade exterior e poder mais alto; subordinam-se lhe as leis e os interesses daqueles domínios mas, por outro lado, é para eles fim imanente, tendo a sua força na unidade do seu último fim universal e dos interesses particulares do indivíduo; esta unidade exprime-se em terem aqueles domínios deveres para com o Estado na medida em que também têm direitos $\left(\S 155^{\circ}\right){ }^{7}$

Desta forma, podemos notar como Hegel crítica veementemente à postura política dos liberais que desejam ter um tipo de Estado sem forças plenas ou como querem os libertaristas atuais de um Estado como guarda noturno ${ }^{8}$. Para este grupo de pensadores a meta a ser implementada é a de que a partir de um determinado momento da história universal os cidadãos consigam viver sem a presença operante do Estado. No pensamento hegeliano que é o anverso desta posição, o Estado ostenta uma espécie de poder calcado na necessidade de sua existência que coteja tanto os interesses do ângulo universal como do ponto de vista particular da vida em sociedade, ou seja, os indivíduos têm diante do Estado tanto direitos que podem ser usufruídos, assim como deveres que devem ser cumpridos tendo em vista o bom funcionamento da vida na sociedade civil. Nesta perspectiva notamos importância que Hegel concede a figura atuante do Estado e de sua presença efetivamente dialética que mantem em tensão a vida ativa da individualidade e da coletividade no arcabouço funcional da sociedade civil.

\footnotetext{
${ }^{7}$ HEGEL, G. W. F. 1770-1831. Princípios da filosofia do direito / G.W.F. Hegel; tradução Orlando Vitorino. - São Paulo: Martins Fontes, 1997, p. 226.

${ }^{8}$ FONSECA, R. "Libertarismo". In: ROSAS, J. C. (Org.). Manual de filosofia política. $2^{\mathrm{a}}$ ed. rev. e aumen. Coimbra: Edições Almedina, 2013, p.65.
} 
$\mathrm{Na}$ compreensão hegeliana o Estado tem grande operativo valor no seio da sociedade civil que é apenas um vetor de condução da realização do seu plano político. Desta forma não existe a possibilidade de a vida humana ser despolitizada como querem os liberais. A filosofia política de Hegel valoriza o Estado como espaço de realização da políticidade na ação em comunidade que é algo vital e está arraigado na práxis dos indivíduos. O poder estatal no pensamento de Hegel não é exercitado de forma autoritária ou de modo monolítico, pois este poder na intenta fazer a regulação da vida dos cidadãos em sua condição primária de liberdade. O Estado hegeliano não exerce uma espécie de poder que fere a liberdade individual das pessoas em sociedade e muito menos deseja ficar controlando os rumos a serem tomados pelos seus membros conforme a volição do soberano. A proposta hegeliana é a de que haja uma espécie de garantia de liberdade para a vida dos indivíduos que transcenda a mera noção de direito à liberdade em termos jurídicos. Cabe ao Estado garantir as condições legais e assegurar a possibilidade de liberdade no agir dos civis em sociedade como fundamento central de suas transações no período histórico dos modernos ${ }^{9}$. Hegel não suprime a liberdade individual presente no coração da sociedade civil, pois a capacidade de possuir propriedades e ser empreendedor requer certo tipo de distanciamento da parte do Estado e, a ampliação da consciência da necessidade de fomentação das relações de intersubjetividade dos seus cidadãos. Isto garante que o Estado na visão hegeliana mantenha a sua supremacia em questões de ordem política, algo que certamente deve ser tarefa mediadora do Estado, mas que não legitima qualquer tipo de totalitarismo ${ }^{10}$.

É importante frisar que na crítica de Hegel aos elementos liberais da autonomia e da liberdade de gestão da sociedade civil não há a pretensão de se desqualificar tais valores, pois as pessoas em suas individualidades podem realizar o seu bem estar privado. Contudo, Hegel se insurge contra a noção liberal de que a sociedade civil tenha alguma vantagem sobre o Estado e que este tenha uma tendência negativa ou como se ele fosse um mal inevitável e ainda um mero instrumento das tramas e interesses individuais. A partir do momento que a sociedade civil não realiza a resolução de suas mazelas sociais, o Estado tem a obrigação de agir para que haja a manutenção de um determinado equilíbrio social, pois isto preservará a existência da sociedade e a plena operatividade da vida privada e coletiva da mesma. O Estado é muito importante para Hegel quando este utiliza o seu poder para freiar o desmantelamento social e 
econômico, evitando que os indivíduos naufraguem e deixem de realizar de modo pleno as suas aspirações ao longo de suas vidas dentro do governo do Estado como sujeitos por excelência ${ }^{11}$. Então, podemos compreender que Hegel tenta preservar em sua noção de Estado a questão da liberdade subjetiva e intersubjetiva na disposição social moderna. Esta concepção pode se realizar na sociedade civil e burguesa moderna em termos de autonomia e liberdade que se relaciona dialeticamente com os deveres civis tanto coletivos como individuais perante o Estado.

A crítica de Hegel ao liberalismo político focaliza e toma como fio condutor a concepção daquilo que seja o ideal de Estado e o poder político para o filósofo moderno, isto é, o eixo das proposições hegelianas sobre o poder estatal está centrado na categoria filosófica da eticidade. O Estado na filosofia do direito hegeliana tem um caráter positivo em sua configuração de poderio político, isto significa que para Hegel o Estado não pode servir de instrumento para a obtenção de benefícios espúrios da parte da sociedade civil ou que esta tenham algum tipo de superioridade ante o Estado, pois se assim o fosse o caráter político do Estado seria anulado ou o Estado seria aparelhado por um grupo de pequenos grupo de burgueses liberais. Nesta argumentação em prol de um Estado positivo é que se evidencia a crítica de Hegel ao liberalismo político, porque o pensador germânico não concebe a noção de que a sociedade civil tenha condições de por si mesma elaborar modelos de autogestão da situação econômica, jurídica e do poder político estatal. Em razão disto, na visão hegeliana não é prudente pode deixar de lado o Estado como instituição forte como o quer a tradição política liberal ${ }^{12}$.

Hegel não assume conscientemente a pressuposição epistemológica do liberalismo político que se fia no aspecto e no entendimento de que haja uma espécie de consenso contratual entre as partes num sentido de ser destituída de conflitos. Quando o filósofo faz a distinção entre direito, ética e política ele está operando por meio de uma espécie de organização interna da filosofia do direito que culmina na sua divisão entre direito abstrato, moralidade e eticidade. Isto mostra que existe um encadeamento rigorosamente lógico entre estas partes, porém, ressalte-se o afã especulativo hegeliano que deseja visualizar na figura do Estado moderno a implantação nítida e a realização concreta do poder político intencionalmente estabelecido por esta instituição. Sendo assim, a filosofia política de Hegel tem o seu desdobramento de alguma maneira para

${ }^{11}$ LUFT, E. Para uma Crítica Interna ao Sistema de Hegel. Porto Alegre: EDPUCRS, 1995, p. 167-169.

${ }^{12}$ RAMOS, 1995, p. 116. 
além da questão política, pois trabalha com a noção de autonomia, mesmo que esta se esvaia na racionalidade estatal moderna que acaba normatizando a mesma. É por isso que Hegel não rejeita o axioma da normatividade, ele rechaça apenas o que se põe como entendimento abstrato em termos solipsistas como é o caso do liberalismo político. Esta argumentação se pauta no valor liberal que defende a separação entre a norma, a lei e o direito de sua base racional e da política estatal. Cabe afirmar que a categoria de universalidade busca pautar o ritmo da norma e não a máxima da particularidade defendida pelos liberais em um movimento de anulação candente de todo e qualquer tipo de universalidade. É por isso que a visão política de Hegel que é condicionada pela logicidade universalista da normatividade, nega o a priori da lógica individualizante da política liberal, quer seja diante da categoria de Estado em si mesma ou do próprio poder político que esta detém positivamente ${ }^{13}$.

Como estamos percebendo, Hegel pode ser considerado um crítico hora moderado, hora severo do liberalismo político. Mesmo que ele assuma alguns pressupostos do mesmo como é caso do contrato e que neste artigo não estaremos desenvolvendo devida a complexidade do assunto que requer uma abordagem criteriosa e não se constitui como nosso tema epistemológico em específico. Ademias, outro pensador que também se levanta como um algoz severo e crítico das sociedades democráticas liberais em sua expressão de sociedade democrática de direito que na noção de espetáculo a sua verve é o filósofo italiano Giorgio Agamben. Enquanto Hegel é um crítico moderado do liberalismo político, no tópico abaixo tentaremos expor alguns elementos da crítica corrosiva que a filosofia agambeniana tece ao liberalismo político. Nesta perspectiva temos que levar em conta algumas questões presentes no seu pensamento desde a sua construção arqueo-genealógica, fundamentalmente, a parti de seu projeto Homo Sacer. Entendo que desta forma poderemos justificar o tema proposto neste artigo que não tem a pretensão de tratar deste problema político-filosófico exaustivamente, porém, tem sim a meta estabelecida de elucidar razoavelmente a crítica que ambos os pensadores tecem ao liberalismo político tendo em mente os seus pressupostos individualizantes e de uma política estatal de caráter minimalista.

\section{Agamben e o seu vitalismo crítico ao liberalismo político}

\footnotetext{
${ }^{13}$ MASCARO, A. L. Filosofia do direito. São Paulo: Atlas, 2010, p. 255-258.
} 
Ao longo da história da humanidade e ainda mesmo nos dias atuais, boa parte da filosofia tem se ocupado com o exame crítico do regime de governo ao qual estamos vivendo. O pensamento político seja este cotejado desde o ponto de vista filosófico ou jurídico, algo que atualmente tem sido hegemonicamente utilizado no expediente ativo da política do liberalismo político. Ainda que tal expediente não seja estritamente referendado como o viés do liberalismo clássico ou o de matriz economicista chamado neoliberalismo. O que se torna evidente é o fato de que tem sido cada vez mais raro encontrar uma crítica veemente ao sistema capitalista e ao Estado de direito instituído e garantido pelas bases jurídicas em de legalidade e legitimidade. O máximo que se propõe é uma postura reformista dentro das instituições políticas atreladas ao viés da democracia liberal. O paradigma que se ergue como exemplo de eficiência dentro das democracias é o de modelo político e econômico liberal. O que marca este paradigma é a categoria de política de Estado de direito, porque isto envolve a territorialização da ênfase jurídica e estatal diante dos afazeres dos cidadãos que são detentores de propriedade privada. Sendo assim, o que advém como implicação de tudo isto é o fortalecimento de sua liberdade individual em detrimento das questões de ordem coletiva, pois isto se torna algo que fornece as suas aspirações empreendedoristas enormes possibilidades e o ato de acumulação de capital acaba gerando um consequente desnível social em termos econômicos ${ }^{14}$.

Agamben não tece a sua crítica ao liberalismo apenas postulando a defesa de um Estado de direito forte e que garanta a legitimidade no que concerne às conquistas jurídico-políticas. Menos ainda o filósofo italiano defende a noção de que haja qualquer tipo de garantismo que sustente como base o bem comum e a inclusão da vida destituída de dignidade nesta arquitetura social democrática tendo em vista os cálculos biopolíticos de gestão da vida. É importante sublinhar que Agamben recebe forte influência da escola crítica frankfurtiana e de modo mais especifico do filósofo germânico Walter Benjamin. Outro pensador que serve como fonte de suas perspicazes ponderações biopolíticas é o francês Michel Foucault. A problemática que Agamben enfrenta é aquela que a tradição da teoria crítica já havia posto em pauta ao considerar o pensamento político liberal deveras reducionista no que diz respeito à própria política em suas possibilidades inauditas. Política esta que para Agamben tem o poder de fazer

\footnotetext{
${ }^{14}$ NETO, P. M. "Estado de direito e estado de exceção: as diferenças entre Agamben e o liberalismo". In: Revista Profanações. Santa Catarina, ano 1, n.1, p. 4-21, 2014. Disponível em: <<http://www.profanaçõesrevista01.pdf〉>. Acesso em: 8 dez de 2014.
} 
ruir e erigir as mais diferenciadas instituições e posturas políticas na vida em sociedade $^{15}$. A crítica de Agamben ao liberalismo político tem um forte tom metafísico, pois ele tenta fazer um diagnóstico do presente com categorias da teologia e da própria metafísica antiga. Para tanto este autor utiliza uma série de conceitos que tentam dar conta desta empreitada crítica que não são usuais neste tipo de procedimento. Fato é que Agamben não se contenta em ser um crítico da democracia liberal e dos direitos humanos, o filósofo italiano problematiza no sentido de colocar em tensão cada vez mais intensamente a questão mais ampla que envolve o paradigma do estado de exceção. Agamben busca aprofundar o debate político na construção de uma ontologia do presente ${ }^{16}$.

A noção de contrato estabelece para a ideologia liberal as condições de possibilidade de acordo consensual entre as partes contratantes. Agamben reflete e problematiza em vários momentos de sua obra esta questão referente à tradição liberal contratualista. Ao realizar um trabalho arqueo-genealógico o pensador italiano se propõe reconstituir as origens paradigmáticas da história de tudo aquilo que deu sustentação ao erguimento do modelo adota no que tange, por exemplo, a questão da economia nas democracias liberais atuais. Aqui temos uma distinção em relação às postulações idealistas dos políticos liberais que depositaram toda a sua esperança na ideia de que foram por meio da noção de contrato social que as sociedades democráticas tiveram as suas origens e o seu progresso. Agamben retoma as pressuposições de Foucault e Arendt que dizem respeito ao cerne da questão que envolve as técnicas políticas e as formas de subjetivação, isto implica na análise das relações entre a biopolítica e a soberania. O filósofo italiano taralha com estas questões, pois visa dar continuidade às pesquisas sobre a questão da força que os dispositivos biopolíticos exercem no formato de poder soberano. Tal empreitada desvela um tipo de correlação espinhosa que envolvo o horizonte de problemas copulados ao esquema jurídicoinstitucional de políticas do Estado de direito democrático ${ }^{17}$. Uma figura paradigmática presente no pano de fundo das questões de ordem biopolíticas que são traçadas por

\footnotetext{
${ }^{15}$ DELACAMPAGne, C. A Filosofia Política Hoje: idéias, debates, questões. Rio de Janeiro: Jorge Zahar Ed., 2001, p. 75-76.

16 NASCIMENTO, D. A. "Do conceito de inoperosidade no recente vulto de Giorgio Agamben". In: Cadernos de Ética e Filosofia Política 17, 2/2010, pp.79-101. Disponível em: <<http://www.revistas.usp.br/cefp/article/viewFile/55708/59124>>. Acesso em: 29 mai de 2015.

${ }^{17}$ CASTRO, E. Introdução a Giorgio Agamben. Uma arqueologia da potência. São Paulo: Autêntica, 2012, p. 59.
} 
Agamben é o mitológico "homo sacer"18. Este "homo sacer" é a transfiguração precisa da "vida nua"19 que é matável, porém, insacrificável. Isto nos mostra a capacidade perspicaz de operatividade do soberano em tratar a vida como uma mera vida. Este tipo de tratamento pode ser rastreado com muita nitidez no desdobramento dos regimes totalitários no século passado e ainda nas democracias que recebem a alcunha de serem chamadas de liberal em seu procedimento de banalização da dignidade da vida humana qualificada. No fundo o que entra em jogo é a vida como objeto das relações de poder e conteúdo do contrato.

Para Agamben o Estado se relaciona com a vida nua do homo sacer em forma de puro abandono, isto é, o poder estatal promove uma situação de exclusão- inclusiva, onde da mesma maneira é que no estado de exceção, a vida somente é incluída para logo em seguida ser excluída e capturada em sua condição de abandono. A força de lei atinge as vítimas do poder repressor do Estado de direito liberal, de modo que o campo se mostra como o espaço vazio do sem lei, onde o poder soberano age no controle dos corpos sem qualquer tipo de observância mediada por normas. A base operacional da norma jurídica não comtempla a possibilidade de realização da narrativa de história que defendam a vida das vítimas, porém, coteja a potência sutil do poder que a todo instante oferece subsídios de força de lei para o soberano. O que se tem é uma fundamentação da política com estruturas fincadas nos valores da democracia pautada pelos pressupostos de uma política liberal. O Estado com o seu aparato jurídico-político é encarado aqui como aquele que tem a tarefa de defender a vida do cidadão comum ou a vida nua, esta

\footnotetext{
${ }^{18}$ RUIZ, C. B. A sacralidade da vida na exceção soberana, a testemunha e sua linguagem: (Re) leituras biopolíticas da obra de Giorgio Agamben. Cadernos IHU, São Leopoldo, ano 10, n. 39, 2012, p. 4: Para corroborar sua tese, Agamben faz uma análise genealógica da figura arcaica do direito romano, o homo sacer. O homo sacer era uma figura jurídico-política pela qual uma pessoa, ao ser proclamada sacer, era legalmente excluída do direito (e consequentemente da política da cidade). A condição de sacer impedia que ela pudesse ser legalmente morta (sacrificada). Porém qualquer um poderia matá-la sem que a lei culpasse o autor por isso.

${ }^{19}$ NASCIMENTO, D. A. Do fim da experiência ao fim do jurídico: percurso de Giorgio Agamben. São Paulo: LiberArs, 2012, p. 168: Se a relação de bando é o elemento originário da constituição jurídica, uma força que liga os pólos da exceção soberana, quais sejam, a vida nua e o poder soberano, "é estrutura de bando que devemos aprender a reconhecer nas relações políticas e nos espaços públicos em que ainda vivemos. Mais íntimo que toda a interioridade e mais externo que toda a estraneidade é, na cidade, o banimento da vida sacra [...] E, se, na modernidade, a vida se coloca sempre mais claramente no centro da política estatal ( que se tornou, nos termos de Foucault, biopolítica), se, no nosso tempo, em um sentido particular mas realíssimo, todos os cidadãos apresentam-se virtualmente como homine sacri, isto somente é possível porque a relação de bando constituída desde a origem a estrutura própria do poder soberano" nesta linha de argumentação, temos que, sendo a relação de exceção a origem mesmo do princípio de soberania, sendo o conceito de soberania ainda um dos principais alicerces do edifício jurídico-político da modernidade, toda relação política guarda a memória de uma estrutura de abandono, tonada evidente com o exame da situação do homo sacer. O que resta da relação soberana, a vida nua, se alastra por todo o universo político. Estamos diante do conceito de vida nua.
} 
seria outra fábula falaciosa propagada pelas democracias que adotam políticas liberais ${ }^{20}$. Esta situação revela-se como um tipo contunde de atividade biopolítica entre a pessoa que têm direitos e o sujeito privatizado em si mesmo. Aqui o direito de cidadão só lhe indica que ode ver de produzir e consumir o que estiver dentro de suas possibilidades, dado que a sua vida encontra-se numa situação de ser administrada por uma política de financeirização. Então, o resultado disto é o de que as vidas dos sujeitos na contemporaneidade estão lançadas cada vez mais em zonas de indistinção de pura anomia.

Uma gama significativa de intérpretes tem compreendido que Agamben ao defender a vida nua do homo sacer, tem se fiado no garantismo constitucionalista que se encontra dentro dos moldes liberais e na linha dos direitos humanos que intenta a defesa das minorias. Porém, outro viés propositivo de interpretação pode ser identificado na obra de Agamben, a partir do momento em que ele traz a tona à categoria filosófica peculiar ao seu pensamento que é a noção de existir daquilo que se chama de "política que vem" ${ }^{21}$. Nesta perspectiva Agamben apresenta este viés da política no sentido aquela que vem como um amplo canteiro de possibilidades diante das aporias políticas encontradas nas democracias liberais.

Na perspectiva de Agamben a proposição de uma política que vem estabelece à colocação explícita da fissura causada com os clássicos conceitos ligados a política tradicional e ao direito praticado nas sociedades democráticas como é o caso, por exemplo, das categorias de nacionalidade ou soberania. Na ótica de Agamben os elementos conceituais que foram erguidos pela percepção da metafísica e da construção teológica tradicional não conseguiram evitar as barbáries do século XX. Tais barbáries permanecem ocorrendo até os dias atuais enquanto a sociedade do espetáculo se contenta em festejar uma pseudo-harmonia-social. O estatuto metafísico do contrato social requer normativamente a participação do cidadão postulando a máxima do

\footnotetext{
${ }^{20}$ BAZZANELLA, S.L; ASSMANN, S.J. “A máquina / dispositivo política: a biopolítica, o estado de exceção, a vida nua”. In: LONGHI, A. J (Org.). Filosofia, política e transformação. São Paulo, SP: LiberArs, 2012, p. 80.

${ }^{21}$ BAZZANELLA, S.L; ASSMANN, S.J. A vida como potência a partir de Nietsche e Agamben. São Paulo, SP: LiberArs, 2013, p. 182: A política que vem é a manifestação de uma potência comum presente no humano. Dessa forma, comunidade e potência se identificam, na medida em que a potência é constitutiva de toda e qualquer perspectiva comunitária e, portanto política. Ou seja, a condição do humano em sua potencialidade e abertura originária, somente se mantém em sua potencialidade e abertura para o mundo quando potencializa politicamente sua potência nas relações de comunicabilidade que estabelece como os demais seres humanos em seu em torno. Nesse sentido, a política que vem, vem das experiências políticas potenciais que brotam da comum comunicabilidade que os homens estabelecem entre si diante dos desafios que apresentam em ato às formas de vida que vem.
} 
consenso, isto gera uma dinâmica que continuamente captura maquinalmente com o dispositivo econômico a vida nua das vítimas em sua humanidade como potência de não ${ }^{22}$. Logo, o vitalismo crítico de Agamben se dirige ao liberalismo no sentido de que este sistema político tende a absolutização de uma forma de governo imanente voraz que descontrói todo tipo de horizonte possível de transcendência. O que importa para o liberalismo político é imanência das questões de ordem econômica e com isso o providencialismo exercido pelos cálculos biopolíticos de gestão da vida e conduta dos corpos.

Para Agamben o estado de exceção esteve escondido nos porões políticos da modernidade. Ele crítica Hobbes ao dizer que o estado de natureza é na realidade o verdadeiro estado de exceção que legitima a decisão soberana. Em nosso país temos uma gama de exemplos fidedignos desta ilusão que o liberalismo propaga de que o contrato social irá dar condições iguais para que todos tenham direitos iguais. O Estado brasileiro ainda não se tornou totalmente liberal, apesar de se julgar liberal. Pensemos naquele contingente de pessoas que vivem em situações deploráveis e que não veem os seus direitos fundamentais sendo atendidos pela constituição liberal que garante a igualdade entre todos em sua individualidade por decreto de lei. Mas, o que se vê é uma sociedade hierarquizada onde alguns grupos dentro deste esquema social tem a força de reativar e transcender a força da lei e das normas. O grande trunfo de muitos setores do poder político brasileiro tem sido a noção de contrato social $\mathrm{Na}$ filosofia agambeniana o processo de profanação, ou seja, a máxima de que deve ocorrer uma destituição da coisa do âmbito do sagrado para que se traga a mesma para o uso comum deveria ganhar espaço dentro da vida política democrática por meio da categoria de profanação ${ }^{23}$. Assinala Agamben:

\footnotetext{
A profanação implica, por sua vez, uma neutralização daquilo que profana. Despois de ter sido profanado, o que estava indisponível e separado perde a sua aura e acaba restituído ao uso. Ambas as operações são políticas, mas a primeira tem a ver com o exercício do poder, o que é assegurado remetendo-o a um modelo sagrado; a segunda desativa os dispositivos do poder e devolve ao uso comum os espaços que ele havia confiscado.
}

O resultado desta proposição no que diz respeito à profanação da política vigente indica que a tarefa de dessacralização da noção constitucionalista liberal que marca o tom de uma postura jurídica que é apenas estudada e não praticada. Mesmo que este não

\footnotetext{
${ }^{22}$ AGAMBEN, G. O reino e a glória: uma genealogia teológica da economia e do governo: homo sacer, II, 2. São Paulo: Boitempo, 2011, p. 308.

23 AGAMBEN, G. Profanações. São Paulo: Boitempo, 2007, p. 68.
} 
alcança efetivamente os seus objetivos que seriam os de beneficiar a vida do viventes em sociedade. Para Agamben, o direito não é a tábua de salvação da humanidade. O que o pensador denota veemência é a possibilidade de se transcender o direito para que se alcance a noção de um novo uso das coisas que está para além da norma jurídica. Agamben relativiza a noção liberal de cidadão e segue adiante com a formulação de uma concepção de política ligada ao devir e que deseja dar conta das demandas que a vida fragilizada como é o caso do paradigma do "homo sacer", que atualmente se manifesta nas vítimas da injustiça e que o mundo maravilhoso do capitalismo tecnocrata liberal não consegue comtemplar com as suas benesses. Para Agamben a vida que se torna alvo de vários sacrifícios que giram em tono do uma polítipa que seja eficiente economicamente. A partir daí o filósofo italiano propõe a profanação destas políticas de “dispositivo" 24 sacralizadas, pois desta forma haverá uma espécie de ação no sentido de ser como que um tipo de contradispositvo que visa devolver ao uso comum àquilo que o sacrifício do contrato liberal acabou separando e dividindo ${ }^{25}$.

Relevante análise na perspectiva da teologia econômica Agamben realiza sobre a possibilidade do cumprimento de tarefas históricas da parte do ser humano e da parte dos Estados-nação que desde a primeira Guerra Mundial colocou em grande ameaça a evolução e o avanço da espécie humana dentro de nossa esfera planetária. Com isto, temos as condições necessárias para compreendermos as experiências dos regimes totalitários no bojo do século XX. Pois neste caso, conforme Agamben é o derradeiro ocaso de perseguição das últimas metas estabelecidas pelos Estados-nações do século XVIII na perspectiva de implantação do nacionalismo e imperialismo. Entretanto, segundo o filósofo italiano, o que estaria de verdade em disputa é algo completamente mais amplo e distinto. O que se trata de fato é a postura de assumir como tarefa a existência de um modo factualmente preciso e que não nega a realidade dos diversos

\footnotetext{
${ }^{24}$ JÚNIOR, W.K. "Giorgio Agamben e as noções de dispositivo, amizade e a busca pela visão na obscuridade do presente para entender o contemporâneo". In: Trama interdisciplinar - ano 1 - Volume 2 -2010, pp. 183-184: O primeiro deles traz, assim como o título da obra, um questionamento - o que é um dispositivo? -, inserindo-nos em uma incursão do termo dispositivo em Michel Foucault, ampliando a análise para um contexto histórico, passando por questões de ordem de genealogia teológica e desencontros de tradução do termo grego oikonomia, traduzido pelos padres latinos como dispositivo, chegando até a própria definição do autor acerca do tema central proposto. O dispositivo para Agamben é compreendido como criação e proliferação de mecanismos da política contemporânea para controlar a conduta e as opiniões de todos os seres humanos na sociedade capitalista. Essa conferência foi apresentada pela primeira vez em 2005, na passagem do filósofo pelo Brasil. Disponível em: $<<$ file:///C:/Users/Usu\%C3\%A1rio/Downloads/3125-11808-1-PB\%20(1).pdf〉〉. Acesso em: 13 jun de 2015.

${ }^{25}$ ANTELO, R. "Profanações". In: ALBERTO, P (Org.). Nove abraços no inapreensível: filosofia e arte em Giorgio Agamben. Rio de Janeiro: Beco do Azougue: FAPERJ, 2008, p. 243.
} 
povos. Isto significa que é a vida nua de milhões de vidas que são manipulas por meio das operações biopolíticas presente no cerne dos Estados liberais. Nesta senda é que se constituíram os totalitarismos do século XX apregoando o fim da história, de modo que a postura de mentalidade e conduta era a de que o ser humano teria atingido a meta histórica terminal sem a possibilidade da existência de outra. Logo, Agamben enceta a crítica que nestas condições a raça humana estaria atingindo novamente a sua condição animalesca genética. Este fenômeno estaria se dado desta forma, em razão do alargamento sem precedentes da oıкovouí $\alpha$ ou ainda por meio da categorização da vida biológica como puro objeto de objetivação e captura da parte das políticas de gestão da vida que fazem viver e deixar morrer. De modo que esta forma que o poder ganhou tem de ser encarada como a operação previdente da biopolítica vigente que elegeu a vida como sua vítima objetiva suprema ${ }^{26}$.

A filosofia política de Agamben é crítica do liberalismo político quando não aceita o garantismo jurídico que reafirma a sistematização feita pelo controle dos dispositivos da norma e da lei. O papel do direito no sistema capitalista democrático liberal que tem como força motriz as garantias que o sistema judiciário tem a oferecer. Para Agamben o direito tal como é colocado hoje, precisa ser ultrapassado e isso na perspectiva de uma política que vem. A categoria que poder ser utilizada para tal tarefa é a da profanação daquilo que está posto e não oferece resultado para a construção da felicidade numa junção entre a regra e a forma-de-vida que determina qual irá ser a norma a ser seguida. Enfim, podemos dizer que Agamben não oferece uma resposta categórica para a problemática da vida vitimizada, mas o filósofo italiano propõe uma nova teoria da ação política que a fissura entre o liame do direito e da vida ou entre a distinção do contrato e da vida sejam uma realidade. A provocação que emerge desta crítica ao liberalismo político transita entre a relação da política que identifica o estado de exceção como produto de uma zona de indiscernibilidade que uma exclusão inclusiva da vida humana como bando. O modelo de poder político fomentado pelo liberalismo político clássico de ser um poder detido pelo soberano, apenas produz a vida nua como uma espécie de elemento politizado que se encontra na fronteira natural entre da vida ou a sua condição qualificadamente cultural e política por excelência. ${ }^{27}$ Algo que rebate a massiva despolitização da vida que os ideólogos liberais propuseram com a noção de

${ }^{26}$ AGAMBEN, G. O aberto: o homem e o animal. Rio de Janeiro: Civilização Brasileira, 2013, p.124125.

${ }^{27}$ AGAMBEN, G. Homo sacer: O pode soberano e a vida nua I. Belo Horizonte: UFMG, 2010, p. 176. 
fim da história. A noção de campo como paradigma da moderna biopolítica, conforme a tese de Agamben indica que as políticas liberais modernas geraram uma concepção de vida natural ou nua não politizada.

Nesta dimensão biopolítica é que a economia política moderna se movimentou no governo dos corpos. O rechaço de Agamben ao poder do Estado democrático com a sua pretensão liberal de individuação da vida em termos de uma espécie de economização da política com a noção metafísica de mão invisível não passa de ser uma falácia. Tudo isto serve apenas as pretensões seja do Estado ou de grupos dentro da sociedade do espetáculo que tem o intuito de governas as práticas e condutas das pessoas. Então, a crítica de Agamben ao liberalismo se defronta com a noção de o contrato ser a regra eficiente para solucionar os problemas da vida. Mas, a forma-devida não se confunde com a regra do contrato, pois a vida tem a potência de não e está liberada para discernir as características e as estratégias da ideologia política liberal ${ }^{28}$. Em síntese, Agamben em sua crítica ao liberalismo político realiza a indicação de que em suas pesquisas que a filosofia como forma-de-vida implica num tipo de ética que levanta o questionamento da norma ou do contrato liberal como uma forma de vida que não serve de paradigma para a constituição ética do sujeito contemporâneo. O que salta aos nossos olhos é a prática ética a que o sujeito contemporâneo é desafiado a criar como norma-de-vida para si mesmo, sem submeter a sua vida a uma norma ou contrato, propiciando assim uma forma-de-vida que cria a sua própria norma de viver.

\section{Considerações Finais}

Encerramos este trabalho denotando que Hegel entende que o Estado é importante e que deve ser um aparato forte e que não pode suprimir a individualidade da sociedade civil burguesa. No caso de Agamben o Estado democrático de direito é um mito, pois este não protege a vida nua das vítimas, mas apenas controla biopoliticamente a vida em suas operações de ordem a fazer viver e deixar morrer. Alguns intérpretes tem entendido que Agamben ao postular a importância de uma prática de defesa da vida com a prerrogativa dos direitos humanos, assim como Hegel, defende a força a noção de um Estado forte. Enquanto Hegel trabalha dialeticamente com a mediação entre o universal estatal e o individual burguês civil. Agamben propõe a noção da construção de uma prática que seja pautada pela sua proposição de uma

${ }^{28}$ AGAMBEN, G. Opus Dei. Arqueologia do ofício. Homo Sacer II, 5. São Paulo: Boitempo, 2013, p. 9. 
política que vem. Agamben crítica veementemente à entidade metafísica (mão invisível) do contrato social como uma espécie de espólio de uma tradição que tratou maquinalmente a vida como vida nua e não deu à devida importância a tradição das vítimas.

Para o pensamento de Agamben a perspectiva que apresenta a noção de bando como aquilo que diz respeito em hipótese alguma ao lema liberal contrato social, porém, a política incita a inclusão exclusiva da vida nua, através de uma relação banalização e de abandono da mesma. Ou seja, dizendo mais explicitamente, a situação do bando é propriamente a força, simultaneamente atrativa e repulsiva, que faz a junção dos dois pólos da exceção soberana: a vida nua e o poder, o homo sacer e o soberano. Esta desproteção da vida, esse "estar atirado à própria sorte”, indica as relações primordiais com a lei, que é o abandono, e não um amparo em termos do contrato social defendido pelos entusiastas do liberalismo político. É importante explicar que essa relação de abandono em relação à lei faz do bando também uma virtualidade; ou seja, essa sacralidade da vida torna-se algo que têm as condições necessárias de remeter-se a todos nós a qualquer momento da história humana. Justamente porque as fronteiras entre política e vida não mais se distinguem, pois elas estão numa zono de indiscernibilidade, onde não há como estabelecer certa inatingibilidade isonômica. Isto é, não há "imunidade” contra a vulnerabilidade da sacralidade da vida.

Voltando ao caso de Hegel o Estado além de deter a primazia diante da sociedade civil, este conserva o controle político e econômico desta sociedade sem tolher as aspirações empreendedoras que existem no seio desta sociedade e de seus indivíduos. Mas, isto precisa ser operado dentro de uma dinâmica que diz respeito à liberdade subjetiva das individualidades diante da força institucional. Para Hegel o Estado é a forma moderna de sociedade civil e política. Ele se constitui como uma totalidade fortemente organizada no meio da vida dos indivíduos que cotidianamente exercem as suas funções como seres racionais, em razão disto, estes indivíduos devem prestas contas diante do Estado. O modelo de Estado que Hegel tem como referente é o do Estado prussiano, com toda a sua força e autoritarismo, algo que solapa as pretensões liberais de um Estado enfraquecido, entretanto, Hegel concordo com a proposta de contrato e com as inciativas empreendedoristas dos sujeitos, axiomas que elogiados pelos pensadores do liberalismo político. Quando pensamos naquilo que Agamben traz como proposta em termos de uma política que vem e a investida de profanação da vida 
política atual, que foi sacralizada ao logo dos séculos, temos a proposta objetiva de que haja a constituição de práticas que se revertam em uma nova política que seja dirija à profanação de tudo aquilo que está separado e se tornou sagrado (contrato social), de modo que isto sirva de fomento para o uso comum dos cidadãos de tudo aquilo que se restringe atualmente ao uso de poucas pessoas ou grupos nas democracias atuais.

Caberia então a tarefa de profanar o modelo social estabelecido pelos liberais que tem como fundamento epistemológico o contrato e o individualismo e com seu indevido acento no campo das pressuposições orientadas pela normatividade jurídicopolítica. Desta forma é que se firma a suposta garantia de uma sociedade economicamente sólida. Agamben provoca ao construir a noção de forma-de-vida que indica à inaudita possibilidade messiânica de existir uma espécie de política atrelada a noção de devir. O olhar de Agamben está dirigido às vítimas que são forjadas como vida nua pelo paradigma do estado de exceção que é produzido pelo direito nas democracias da sociedade do espetáculo contemporânea. O ponto de contato entre os dois pensadores aqui trabalhados certamente é crítica ao modelo de sociedade proposto pelo liberalismo político e cada uma faz de sua própria forma. Hegel faz a crítica ao exacerbado acento na individualidade e a não consideração do bem comum por parte dos liberais, isto para ele é um problema, pois desta forma se desconsidera o papel forte e provedor do Estado na modernidade. Já com Agamben a proposta é a de realização de profanação da estrutura política democrática liberal e a irrupção de uma nova política que vem onde a vida e o contrato não se cruzam, porque para o filósofo italiano é a vida qualificada que prepondera sobre as decisões biopolíticas operadas pelo Estado de direito liberal.

\section{Referências}

AGAMBEN, G. Opus Dei. Arqueologia do ofício. Homo Sacer II, 5. São Paulo: Boitempo, 2013.

Brasileira, 2013.

$O$ aberto: $o$ homem e o animal. Rio de Janeiro: Civilização Profanações. São Paulo: Boitempo, 2007.

UFMG, 2010.

Homo sacer: O pode soberano e a vida nua I. Belo Horizonte: 
AGAMBEN, G. O reino e a glória: uma genealogia teológica da economia e do governo: homo sacer, II, 2. São Paulo: Boitempo, 2011.

ANTELO, R. "Profanações". In: ALBERTO, P (Org.). Nove abraços no inapreensível: filosofia e arte em Giorgio Agamben. Rio de Janeiro: Beco do Azougue: FAPERJ, 2008.

BAVARESCO, A. A fenomenologia da opinião pública: a teoria hegeliana. Coleção Filosofia. São Paulo: Edições Loyola, 2003.

BAZZANELLA, S.L; ASSMANN, S.J. "A máquina / dispositivo política: a biopolítica, o estado de exceção, a vida nua”. In: LONGHI, A. J (Org.). Filosofia, política e transformação. São Paulo, SO: LiberArs, 2012.

SP: LiberArs, 2013.

A vida como potência a partir de Nietsche e Agamben. São Paulo,

BORGES. M. L. A. História e Metafísica em Hegel: sobre a noção de espírito do mundo. Porto Alegre: EDIPUCRS, 1998.

CASTRO, E. Introdução a Giorgio Agamben. Uma arqueologia da potência. São Paulo: Autêntica, 2012.

DELACAMPAGNE, C. A Filosofia Política Hoje: idéias, debates, questões. Rio de Janeiro: Jorge Zahar Ed., 2001.

FONSECA, R. “Libertarismo”. In: ROSAS, J. C. (Org.). Manual de filosofia política. $2^{\text {a }}$ ed. rev. e aumen. Coimbra: Edições Almedina, 2013.

HEGEL, G. W. F. 1770-1831. Princípios da filosofia do direito / G.W.F. Hegel; tradução Orlando Vitorino. - São Paulo: Martins Fontes, 1997.

JÚNIOR, W.K. "Giorgio Agamben e as noções de dispositivo, amizade e a busca pela visão na obscuridade do presente para entender o contemporâneo". In: Trama interdisciplinar - ano 1 - Volume 2 - 2010, pp. 183-184. Disponível em: <<file:///C:/Users/Usu\%C3\%A1rio/Downloads/3125-11808-1-PB\%20(1).pdf〉>.

Acesso em: 13 de jun. 2015.

LUFT, E. Para uma Crítica Interna ao Sistema de Hegel. Porto Alegre: EDPUCRS, 1995.

MASCARO, A. L.. Filosofia do direito. São Paulo: Atlas, 2010.

MARX, K. Crítica da filosofia do direito de Hegel 1843; tradução de Rubens Enderle e Leonardo de Deus; [supervisão e notas Marcelo Backes]. - [2.ed revista]. - São Paulo: Boitempo, 2010.

NASCIMENTO, D. A. Do fim da experiência ao fim do jurídico: percurso de Giorgio Agamben. São Paulo: LiberArs, 2012,

"Do conceito de inoperosidade no recente vulto de Giorgio Agamben". In: Cadernos de Ética e Filosofia Política. n ${ }^{\circ}$ 17, 2/2010, pp.79-101. Disponível em: <<http://www.revistas.usp.br/cefp/article/viewFile/55708/59124>>. Acesso em: 29 mai de 2015. 
NETO, P. M. "Estado de direito e estado de exceção: as diferenças entre Agamben e o liberalismo". Revista Profanações. Santa Catarina, ano 1, n.1, p. 4-21, 2014. Disponível em: <<http://www.profanaçõesrevista01.pdf〉>. Acesso em: $8 \mathrm{dez}$ de 2014.

RAMOS, A. C. “A crítica de Schmitt e de Hegel ao liberalismo”. Trans/ Form/Ação, São Paulo, v. 18, p. 105-119, 1995. Disponível em: <<http:www.//revistaseletronicas .trans/form/ação.org.br>>. Acesso em: 06 jan de 2015.

ROSENFIELD, D. L. Hegel, a moralidade e a religião. Rio de Janeiro: Jorge Zahar Ed., 2002.

ROVIGHI, S. V. História da filosofia contemporânea: do século XIX à escolástica contemporânea. Tradução Ana Pareschi Capovilla; $4^{a}$ edição: maio de 2011. São Paulo: Edições Loyola, 2011.

RUIZ, C. B. A sacralidade da vida na exceção soberana, a testemunha e sua linguagem: (Re) leituras biopolíticas da obra de Giorgio Agamben. Cadernos IHU, São Leopoldo, ano 10, n. 39, 2012.

Recebido em dezembro de 2015

Aprovado em fevereiro de 2016 